\title{
SISTEM INFORMASI MANAJEMEN PT. ARMADA PUTRA NUSANTARA BERBASIS WEB
}

\author{
Agus Alim Muin ${ }^{(1)}$, Agus Setiawan ${ }^{(2)}$, Rizqi Elmuna Hidayah ${ }^{(3)}$ \\ ${ }^{1}$ Fakultas Teknologi Informasi, UNISKA \\ Email : agusalimmuin@gmail.com \\ ${ }^{2}$ Fakultas Teknologi Informasi, UNISKA \\ Email : agusteknik90@gmail.com \\ ${ }^{3}$ Fakultas Teknologi Informasi, UNISKA \\ Email : riskyelmunahidayah@gmail.com
}

\begin{abstract}
ABSTRAK
Pada PT Armada Putra Nusantara salah satunya, perusahaana tersebut memerlukan sebuah sistem yang bisa mengelola setiap data tentang fright charter tongkang dan tubgoat serta sistem yang bisa memonitor segala keuangan diperusahaan. Maka dari itulah peneliti berusaha untuk melakukan analisa pada perusahaan tersebut mulai dari merekap semua berkas tentang sewa kapal sampai tentang manajemen pengeluaran kas keuangan. Sebelumnya pemasukan data-data transaksi keuangan dilakukan secara manual menggunakan MS Excel oleh 1 orang staf keuangan dengan formula - formula sederhana. Transaksi keuangan hanya biasa dilakukan pada komputer local yang ada, sehingga bila 1 orang staf keuangan tersebut sedang berada diluar atau tidak masuk kerja, maka transaksi kurang berjalan maksimal. Ini merupakan salah satu hambatan bagi kinerja yang lain, karena data - data tersebut sangat penting untuk mengetahui keadaan keuangan kapan saja dan dalam kondisi apapun. Dengan pembuatan sistem baru ini diharapkan akan mempermudah memproses transaksi keuangan. Para staf lain yang berwenang dapat memproses transaksi keuangan secara cepat, keunggulannya pimpinan dapat melihat keadaan keuangan meskipun tidak berada pada kantor pusat, dan pemeliharaan data dapat dilakukan dengan lebih mudah.
\end{abstract}

Kata Kunci : sistem, informasi, manajemen, keuangan, perusahaan, kapal.

\section{PENDAHULUAN}

Pada PT Armada Putra Nusantara salah satunya, perusahaana tersebut menginginkan sebuah sistem yang bisa mengelola setiap data tentang fright charter tongkang dan tubgoat serta sistem yang bisa memonitor segala keuangan diperusahaan. Maka dari itulah peneliti berusaha untuk melakukan analisa pada perusahaan tersebut mulai dari merekap semua berkas tentang sewa kapal sampai tentang manajemen pengeluaran kas keuangan

Sebelumnya pemasukan data-data transaksi keuangan dilakukan secara manual menggunakan MS Excel oleh 1 orang staf keuangan dengan formula formula sederhana. Transaksi keuangan hanya biasa dilakukan pada computer local yang ada, sehingga bila 1 orang staf keuangan tersebut sedang berada diluar atau tidak masuk kerja, maka transaksi kurang berjalan maksimal. Ini merupakan salah satu hambatan bagi kinerja yang lain, karena data - data tersebut sangat penting untuk mengetahui keadaan keuangan kapan saja dan dalam kondisi apapun. 


\section{RUMUSAN MASALAH}

Berdasarkan latar belakang tersebut dapat dirumuskan masalahnya adalah perlunya sistem informasi manajemen secara komputersisasi berbasis web agar menjadi sistem yang lebih simple, efisien, dan informatif bagi pengguna

\section{TUJUAN DAN TARGET LUARAN}

Adapun tujuan dari penelitian ini, yaitu :

1. Sebagai salah satu tridarma sebagai seorang pengajar yaitu melakukan penelitian

2. Membuat sebuah sistem yang berbasis online sesuai dengan bidang ilmu pendidikan

Target luaran wajib dan tambahan dalam pembuatan penelitian ini yaitu akan dipublikasikan dalam jurnal lokal yang mempunyai ISSN atau jurnal nasional terakreditasi dan sesuai bidang ilmu seperti Jurnal Techonogia

\section{METODE PENELITIAN}

$\begin{array}{cc}\text { Pada penelitian ini penulis } \\ \text { menggunakan beberapa } & \begin{array}{l}\text { metode } \\ \text { pengumpulan data sebagai berikut: }\end{array}\end{array}$

a. Metode Observasi

Observasi atau pengamatan merupakan salah satu teknik pengumpulan data atau fakta yang cukup efektif untuk mempelajari suatu sistem. Observasi adalah pengamatan langsung para pembuat keputusan berikut lingkungan fisiknya atau pengamatan langsung suatu kegiatan yang sedang berjalan. Pada tahap ini penulis melakukan pengamatan terhadap kegiatan, proses, dan alur sistem yang berjalan pada perusahaan tersebut

b. Metode Wawancara
Wawancara merupakan salah satu teknik pengumpulan data yang penting dan banyak dilakukan dalam pengembangan sistem informasi. Wawancara memungkinkan analis sistem sebagai pewawancara untuk mengumpulkan data secara tatap muka langsung dengan orang yang diwawancarai. Adapun orang-orang yang diwawancarai adalah pimpinan, admin data, dan admin keuangan.

\section{ANALISA HASIL DAN PEMBAHASAN}

\section{Hasil Pengumpulan Data}

1. Metode Observasi

Observasi dilakukan 2 kali pada bulan september 2017, dengan tujuan untuk melakukan pengamatan langsung terhadap sistem yang berjalan pada objek yang ternyata masih menggunakan excel dan word

2. Metode Wawancara

Wawancara dilakukan kepada admin pendataan dan admin keuangan. Wawancara lebih banyak dilakukan dengan komunikasi via Chat, karena pihak yang objek sangat sibuk dan sering keluar kota, sehingga tidak bisa untuk diajak wawancara langsung. Wawancara mengenai bagaimana proses sewa kapal

\section{Hasil Temuan}

Hasil temuan yang didapatkan setelah melakukan analisa dan pengumpulan data adalah sebagai berikut :

a. Sistem yang sedang berjalan pada objek penelitian untuk penyimpanan data Sewa kapal menggunakan ms. Word. Hal tersebut kurang efektif untuk suatu perusahaan yang besar karena menpengaruhi dalam 
pelaporan jika pimpinan meminta dengan cepat

b. Untuk sistem keuangan pun masih menggunakan ms Excel, memang objek tidak pernah menggunakan sebuah aplikasi untuk melakukan perhitungan keuangan, permasalahan muncul pada saat pihak pajak meminta laporan keuangan..

\section{Implementasi sistem}

a. Form login

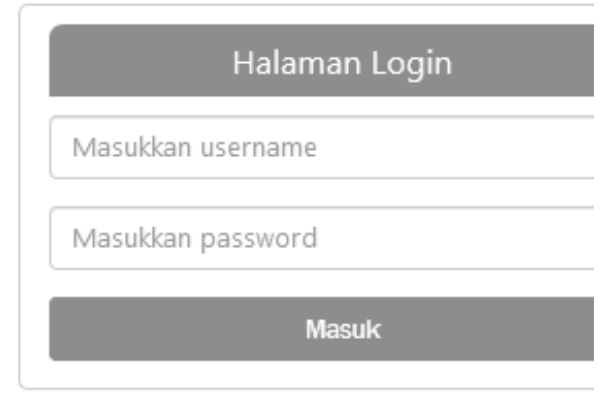

Gambar 1 Form Login

b. Form Data Kapal

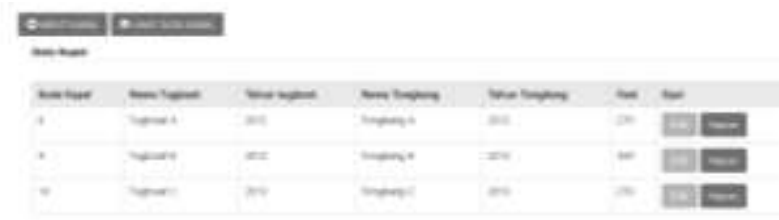

Gambar 2 Data Kapal

c. Form Data Karyawan

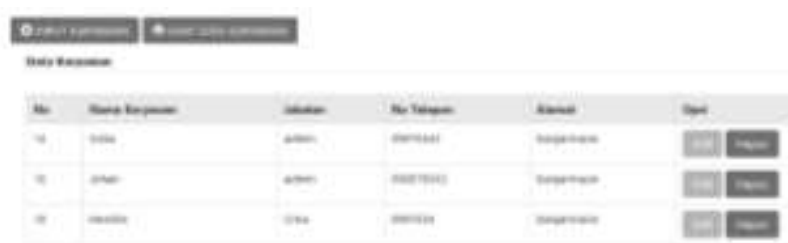

Gambar 1 Data Karyawan

d. Form Data Transaksi

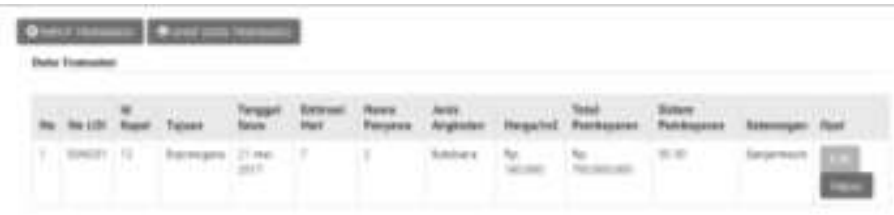

Gambar 2 Data Transaksi

e. Form Data Penyewa

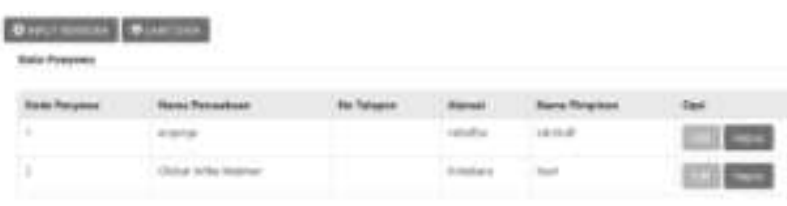

Gambar 3 Data Penyewa

f. Laporan Keuangan

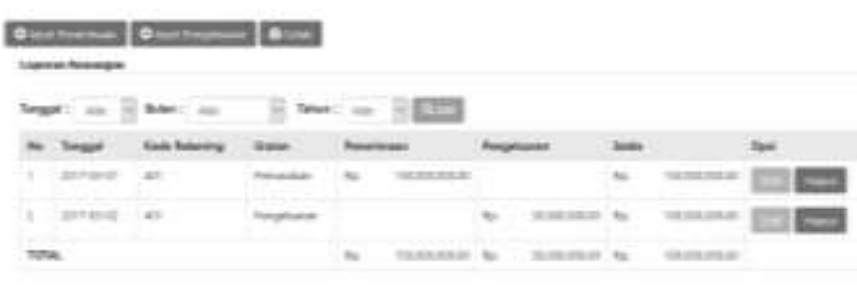

Gambar 4 Data laporan keuangan

g. Laporan Kas

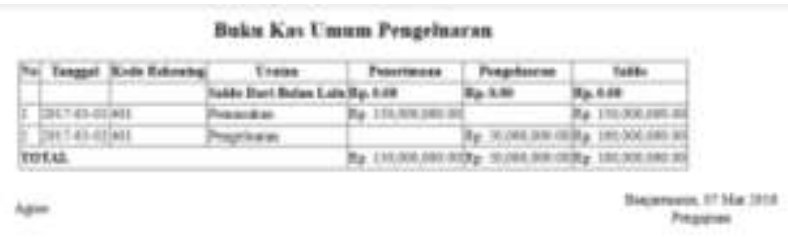

\section{PENUTUP}

\section{KESIMPULAN}

Kesimpulan dari penelitian yang telah dilakukan adalah sebagai berikut :

1. Dengan dibuatnya sistem yang baru ini, penyimpanan data sewa kapal tidak lagi menggunakan ms.word, sehingga 
pelaporan ke pimpinan menjadi lebih mudah.

2. Sistem pelaporan keuangan menjadi lebih mudah dan cepat daripada menggunakan sistem sebelumnya.

\subsection{Saran}

Saran dari penelitian yang telah dilakukan adalah sebagai berikut :

1. Tampilan masih sangat sederhana karena menggunakan template yang pasaran

2. Sistem yang dibuat masih sangat sederhana yang berdasarkan ruang lingkup yang ada, tapi tidak menutup kemungkinan pengembang lain bisa menambahkan beberapa form sesuai keperluan

\section{DAFTAR PUSTAKA}

1] Abdul Kadir. 2010. Mudah Mempelajari Database MySQL. Yogyakarta:Andi Offset

2] Al Fatta, Hanif. 2007. Analisis dan Perancangan Sistem Organisasi: Untuk Keunggulan Bersaing Perusahaan dan Organisasi Modern.
Yogyakarta:Andi Offset

3] Arief, M. Rudyanto. 2011. Pemrograman Web Dinamis Menggunakan PHP dan MySQL. Yogyakarta: Andi Offset

4] Jogiyanto, HM. 2005. Analisis dan Desain Sistem Informasi: Pendekatan Terstruktur, Teori dan Praktik Aplikasi Bisnis. Yogyakarta:Andi Offset

5] Kusrini. 2007. Strategi Perancangan dan Pengelolaan Basis Data. Yogyakarta: Andi Offset

6] Rangga Andriyanto, 2004, Membuat Website Menggunakan Mysql, Andi Offset, Yogyakarta, 2011

7] Peranginangin, K. (2006). Aplikasi $W E B$ dengan PHP dan MySQL. Yogyakarta: ANDI. 